\title{
Exploring the potential of resorcinol-formaldehyde xerogels as thermal insulators
}

\author{
Natalia Rey-Raap, E.G. Calvo, J.A. Menéndez, A. Arenillas* \\ Instituto Nacional del Carbón CSIC, Apartado 73, 33080 Oviedo (Spain) \\ ${ }^{*}$ Corresponding author. Tel.: +34 9851190 90; Fax: +34 985297662 \\ E-mail address: aapuente@incar.csic.es (Ana Arenillas)
}

\begin{abstract}
The contribution to the total thermal conductivity of porous materials depends mainly on the operating conditions and on its type of porosity. Accordingly, the thermal insulating capacities of several resorcinol-formaldehyde (RF) xerogels synthesized by microwave heating were investigated. First, the operating conditions were optimized, since the thermal conductivity measurements were to be performed both before and after the degassing of the organic xerogels and with various particle sizes, ranging from $3 \mathrm{~mm}$ to below $212 \mu \mathrm{m}$. Special attention was paid to the influence of the porous properties, particularly density and pore size, on the total thermal conductivity. A minimum thermal conductivity value of $0.035 \mathrm{~W} \mathrm{~m}^{-1} \mathrm{~K}^{-1}$ was obtained for an organic xerogel with a bulk density of $0.248 \mathrm{~g} \mathrm{~cm}^{-3}$ and a mean pore size of $144 \mathrm{~nm}$. The results obtained suggest that RF xerogels would be highly suitable candidates for thermal insulation applications as their thermal conductivity values are comparable to those of commercial materials, such as expanded polystyrene $\left(0.034 \mathrm{~W} \mathrm{~m}^{-1} \mathrm{~K}^{-1}\right)$.
\end{abstract}

Keywords: Resorcinol-formaldehyde xerogels; Pore size; Density; Thermal conductivity

\section{Introduction}

Insulating materials are used for many applications (thermal packaging, building construction, aerospace industry, etc.) to minimize energy losses, for safety purposes, to enhance the sustainability of industrial processes or even to reduce negative environmental impacts [1-3]. These materials require different properties depending on their final application, which leads to a large number of insulating materials with different benefits and costs. Some of the most widely used insulating materials are cork, polyurethane (PUR), expanded polystyrene (EPS), glass wool or silica aerogels [1-5]. 
The thermal conductivity $(\lambda)$ of a material, i.e. its ability to conduct heat, is determined by the sum of the three mechanisms of heat transfer: radiation, convection and conduction [2, 4-14]. According to literature: i) radiation depends to a great extent on the temperature of the insulating material $[7,11,15,16]$ and hence, under normal operating conditions, the radiation mechanism of some materials exhibits a low extinction coefficient, in which case radiation is negligible $[6,8,13]$, ii) the contribution of convention to the total thermal conductivity depends mainly on the operating conditions $[8,11,15]$ and iii) conduction depends mainly on the interconnectivity of the material, i.e. on the porous structure $[2,4,8,9,11,12,16]$.

In order to obtain the lowest possible total effective thermal conductivity, the three above contributions (radiation, convection and conduction) must be minimized. Each of these heat transfer mechanisms will contribute to the total thermal conductivity as a function of the porous properties of the material and the conditions (pressure, temperature, humidity, etc.) under which they have to operate $[2,8-11,17,18]$. In this regard, resorcinol-formaldehyde (RF) gels are excellent candidates for use as thermal insulating materials since the sol-gel synthesis process allows their porous properties to be meticulously designed [9, 11, 16, 17, 19-23]. Several studies in literature highlight the insulating properties of carbon aerogels $[10,11,13,14,16,19,22]$, while just a few are related to the use of organic RF aerogels [9, 15, 17]. For example, Lu et al. evaluated the thermal conductivity of RF organic aerogels of different density and obtained a minimum value of $\lambda=0.012 \mathrm{~W} \mathrm{~m}^{-1} \mathrm{k}^{-1}$ for a sample with a bulk density of $0.157 \mathrm{~g} \mathrm{~cm}^{-3}[9,15]$. Another more recent example has been published by R. Tannert and co-workers, who reported in 2015 values of thermal conductivity ranging between 0.019 and $0.030 \mathrm{~W} \mathrm{~m}^{-1} \mathrm{k}^{-1}$, at atmospheric pressure, for several organic aerogels produced under different conditions of initial $\mathrm{pH}$ and resorcinol/water molar ratio [17]. In their work, the relevance of pore size distribution on the insulating capacity of materials was clearly demonstrated because two RF aerogels with similar densities and porosity percentages (i.e. 0.10 and $0.12 \mathrm{~g} \mathrm{~cm}^{3}$ and $92-93 \%$, respectively) but different average pore size (171 and $60 \mathrm{~nm}$, respectively) exhibited $\lambda$ values of 0.030 and 0.021 $\mathrm{W} \mathrm{m} \mathrm{m}^{-1} \mathrm{k}^{-1}$.

However, despite having properties suitable for thermal insulating materials, the largescale production of RF aerogels is still very restricted, since the synthesis process involves several steps and requires supercritical conditions to remove the solvent $[9,11$, 
17]. This process entails excessive production costs and, hence, their use is limited to high-tech applications, where their excellent properties take precedence over their high price. In this situation, resorcinol-formaldehyde xerogels come into their own since, in addition to being amorphous materials with a low density and a high porosity, they can be obtained easily by means of microwave radiation [20, 21]. In this way, the costs of production are reduced and it is possible to increase their competitiveness against other materials available in the thermal insulation industry.

In order to properly design the properties of the RF xerogels and be able to use them as thermal insulators, the effect of the three heat transfer mechanisms through these porous materials should be considered. The contribution of radiation for RF xerogels can be considered insignificant $[8,11,12]$, so the total thermal conductivity will depend primarily on the conduction and convection mechanisms. As mentioned above, convection depends mainly on the operating conditions while conduction varies depending on the porous properties. However, it needs to be taken into account that the different porous properties do not affect the mechanism of heat transfer in the same way. For example, heat transfer by gaseous thermal conduction rises as pore size increases, whereas conduction through the solid skeleton decreases as bulk density is reduced, due to the lower connectivity of the solid structure $[8,9]$. Therefore, in order to reduce both contributions and minimize thermal conductivity, that is to say, to obtain a material with an excellent thermal insulation performance, it is necessary to strike a balance between these two mechanisms by means of a careful design of the porous structure of the material.

In this work, the properties of RF organic xerogels were designed in order to obtain materials with different porous structures. These bespoke xerogels were synthesized by means of microwave radiation by adjusting the $\mathrm{pH}$, dilution ratio and resorcinolformaldehyde molar ratio. The thermal insulation capacity of these materials was evaluated in order to determine the influence of the porous properties on the total thermal conductivity. Furthermore, the thermal conductivity measurements were performed with samples of different granulometry, in order to determine the optimal particle size. 


\section{Experimental Section}

\subsection{Sol-gel synthesis of RF xerogels}

A series of amorphous resorcinol-formaldehyde xerogels was prepared by the polycondensation of resorcinol $(\mathrm{R})$ and formaldehyde $(\mathrm{F})$, using sodium hydroxide solutions as catalyst (C) and deionized water (W) as solvent. The sol-gel synthesis process, carried out by microwave heating, is explained in detail elsewhere [20, 21, 2427]. In short, it is a rapid and simple process, performed in a compact microwave oven consisting of two main stages: (i) the RF precursor mixture $(200 \mathrm{~mL})$ is subjected to a temperature of $85^{\circ} \mathrm{C}$ for ca. 3 hours during which polymerization reactions between the monomers $\mathrm{R}$ and $\mathrm{F}$ take place (gelation and curing steps) and, (ii) evaporation of the solvent until a mass loss of $50 \mathrm{wt}$ \% is obtained, this stage generally lasting no more than 2 hours (drying step).

Variables such as the $\mathrm{pH}$, dilution ratio (D) and $\mathrm{R} / \mathrm{F}$ molar ratio were modified in order to obtain a variety of organic xerogels of different porosity, specifically, with different bulk density and pore size. It should be pointed out that the values of $\mathrm{pH}, \mathrm{D}$ and $\mathrm{R} / \mathrm{F}$ were selected on the basis of results previously published by our research group [20, 2426]. In those studies, statistical techniques were employed in order to obtain mathematical models from which it is possible to calculate the concentration of each reagent to be used in order to synthesize materials with the desired properties. Accordingly, the ranges used in this study were from 3 to 6.5 for the initial $\mathrm{pH}$, from 4.7 to 7.7 in the case of the dilution ratio while the $\mathrm{R} / \mathrm{F}$ molar ratio was varied between 0.10 and 0.50. The samples synthesized were labeled as follows: OX (organic xerogel) followed by two numbers corresponding to the value of their bulk density and pore size, respectively.

\subsection{Sample characterization}

\subsubsection{Porous properties}

The porosity of the RF xerogels was investigated using two techniques: (i) adsorptiondesorption nitrogen isotherms, that provide information about microporosity and narrow mesoporosity and, (ii) mercury porosimetry, by means of which it was possible to determine the meso-macroporous structure of the samples analyzed. In both cases, 
before the analysis, the samples were treated at $120{ }^{\circ} \mathrm{C}$ under vacuum $(0.1 \mathrm{mbar})$ for 8 hours.

The surface area $\left(\mathrm{S}_{\mathrm{BET}}\right)$, total pore volume $\left(\mathrm{V}_{\mathrm{p}}\right)$ and micropore volume $\left(\mathrm{V}_{\text {micro }}\right)$ were determined by means of $\mathrm{N}_{2}$ adsorption-desorption isotherms. The analysis was carried out using a Micromeritics Tristar 3020 instrument at $-196{ }^{\circ} \mathrm{C}$. The Brunauer-EmmettTeller and Dubinin-Raduskevich equations were applied to calculate the $S_{\mathrm{BET}}$ and $\mathrm{V}_{\text {micro, }}$, respectively. $V_{p}$ was estimated from the nitrogen adsorbed at $\mathrm{p} / \mathrm{p}^{\mathrm{o}}=0.99$. It must be taken into account that most of the samples presented in this paper have large mesopores and even macropores, hence $V_{p}$ does not correspond to the real total pore volume. Therefore, in order to accurately study the porous structure of these materials, it was necessary to resort to mercury porosimetry.

Mercury porosimetry was performed using an Autopore IV 9500, Micromeritics, apparatus, in a pressure range from atmospheric pressure to $228 \mathrm{MPa}$. In all the experiments, the surface tension and contact angle were adjusted to $485 \mathrm{mN} \mathrm{m}^{-1}$ and $130^{\circ}$, respectively. By means of this technique, which is based on Washburn's intrusion theory, the following parameters were determined: mesopore and macropore volume ( $\mathrm{V}_{\text {meso }}$ and $\mathrm{V}_{\text {macro }}$ ), average pore size $\left(\mathrm{d}_{\text {pore }}\right)$, percentage of porosity and bulk density. It should be mentioned that in the case of $\mathrm{V}_{\text {meso }}$, mesopores were considered to be those with a size larger than $5.5 \mathrm{~nm}$, since this is the lowest limit at which the device can operate.

\subsubsection{Thermal conductivity measurements}

The measurements were performed with a thermal conductivity analyzer (TPS 2200, Hot Disk), using a transiently heated plane sensor fitted with Kapton insulation (radius: $3.189 \mathrm{~mm}$ ) and an isotropic module for low density materials. The measurements were performed on previously degassed samples $\left(120^{\circ} \mathrm{C}, 0.1 \mathrm{mbar}, 8\right.$ hours $)$, in order to remove all moisture and other molecules adsorbed into the inner surface of the material, which might contribute to increasing thermal conductivity. Notwithstanding, the thermal conductivity of an untreated xerogel was also measured for comparison purposes and to assess the effectiveness of the degassing process. Thermal conductivity values $(\lambda)$ were also obtained for materials with different granulometries (particles size ranging from $3 \mathrm{~mm}$ to $<212 \mu \mathrm{m}$ ) in order to identify the particle size that would ensure 
the minimal thermal conductivity. Finally, the thermal conductivity of expanded polystyrene (EPS) was determined. This reference material was selected because it is widely used in the field of thermal insulation.

\section{Results and discussion}

\subsection{Porous properties of RF xerogels}

Table 1 shows the porous properties of the seven RF xerogels synthesized in this work. The results underscore the possibility of preparing a wide range of materials with different pore structure by means of slight changes upon the concentration of reactants. It can be seen from macroporous samples of very low density (as is the case of the OX$0.2-\mathrm{d}_{\mathrm{p}}$ xerogels) to denser xerogels with a micro-mesoporous structure and narrow mesopores size (for example, the sample labeled OX-0.7-11). Except in the case of this latter sample, which has a density value of $0.735 \mathrm{~g} \mathrm{~cm}^{-3}$, the other xerogels reported in Table 1 are highly porous materials with a porosity of over $70 \%$. As pointed out in the Introduction section, a high degree of porosity does not guarantee low values of thermal conductivity, since bulk density of materials also plays a decisive role. This density is defined by both the size and volume of the pores created during the polymerization reaction. Samples with a high volume of large pores have a lower density (for instance, samples OX-0.2- $\mathrm{d}_{\mathrm{p}}$ and OX-0.3-270), while samples become denser as the pore size decreases, as in the case of the other three organic xerogels, which have a porous structure mainly composed of micropores and mesopores. From these data it can be inferred that there is a clear relation between the density of the materials and the size/volume of the pores. Nevertheless, the porous properties can be further tailored by modifying the synthesis conditions. Good examples of this are samples OX-0.2- $\mathrm{d}_{\mathrm{p}}$, which have similar values of density and porosity but totally different mean pore sizes.

Table 1 Summary of the porous properties of the synthesized RF xerogels

\begin{tabular}{|c|c|c|c|c|c|c|c|c|}
\hline \multirow{2}{*}{ Sample } & \multicolumn{3}{|c|}{$\mathrm{N}_{2}$ adsorption-desorption } & \multicolumn{5}{|c|}{ Mercury porosimetry } \\
\hline & $\begin{array}{c}\mathrm{S}_{\mathrm{BET}} \\
\left(\mathrm{m}^{2} \mathrm{~g}^{-1}\right)\end{array}$ & $\begin{array}{c}V_{\text {micro }} \\
\left(\mathrm{cm}^{3} \mathrm{~g}^{-1}\right) \\
\end{array}$ & $\begin{array}{c}\mathrm{V}_{\mathrm{p}}^{\mathrm{a}} \\
\left(\mathrm{cm}^{3} \mathrm{~g}^{-1}\right)\end{array}$ & $\begin{array}{c}V_{\text {meso }} \\
\left(\mathrm{cm}^{3} \mathrm{~g}^{-1}\right) \\
\end{array}$ & $\begin{array}{c}V_{\text {macro }} \\
\left(\mathrm{cm}^{3} \mathrm{~g}^{-1}\right) \\
\end{array}$ & $\begin{array}{c}\mathrm{d}_{\mathrm{p}} \\
(\mathrm{nm})\end{array}$ & $\begin{array}{l}\text { density } \\
\left(\mathrm{g} \mathrm{cm}^{-3}\right)\end{array}$ & $\begin{array}{c}\text { porosity } \\
(\%)\end{array}$ \\
\hline OX-0.7-10 & 484 & 0.18 & 0.60 & 0.37 & $-^{c}$ & 10 & 0.735 & 33 \\
\hline OX-0.6-11 & 445 & 0.15 & 0.80 & 0.53 & $-^{\mathrm{c}}$ & 11 & 0.607 & 70 \\
\hline OX-0.4-40 & 180 & 0.07 & 0.43 & 0.81 & 0.65 & 40 & 0.438 & 75 \\
\hline OX-0.3-270 & 8 & $-{ }^{b}$ & 0.01 & 0.02 & 1.93 & 270 & 0.341 & 76 \\
\hline
\end{tabular}




\begin{tabular}{lcccccccc}
\hline OX-0.2-5000 & 18 & 0.01 & 0.02 & 0.02 & 3.31 & 5000 & 0.226 & 82 \\
OX-0.2-800 & 37 & 0.01 & 0.06 & 0.03 & 2.64 & 800 & 0.204 & 83 \\
OX-0.2-144 & 4 & $-{ }^{-}$ & 0.01 & 0.04 & 3.00 & 144 & 0.248 & 80 \\
\hline
\end{tabular}

${ }^{\mathrm{a}} \mathrm{V}_{\mathrm{p}}$, volume of $\mathrm{N}_{2}$ adsorbed at saturation point $\left(\mathrm{p} / \mathrm{p}^{\mathrm{o}}=0.99\right)$.

${ }^{\mathrm{b}}$ Not relevant.

${ }^{\mathrm{c}}$ Non-macroporous sample.

It should be mentioned that the low-density xerogels have a poorly developed microporosity $\left(\mathrm{S}_{\mathrm{BET}}<40 \mathrm{~m}^{2} \mathrm{~g}^{-1}\right.$ ), a point worth highlighting since samples with a large presence of micropores show a lower capacity as insulating materials due to an increase in heat transfer via the mechanism of conduction, which is a consequence of the higher interconnectivity between clusters (polymeric primary particles formed during the polymerization reaction between resorcinol and formaldehyde [20]). This is one of the reasons why organic xerogels are used instead of carbonized samples, apart from the fact that they are cheaper materials due to the last stage of the manufacturing process is suppressed (i.e. the thermal treatment conducted under an inert atmosphere at temperatures above $700{ }^{\circ} \mathrm{C}$ ).

\subsection{Insulating capacity of RF xerogels}

\subsubsection{Effect of the degassing conditions and particle size}

The first measurements of thermal conductivity $(\lambda)$ were performed in ambient conditions $\left(25^{\circ} \mathrm{C}, 1 \mathrm{~atm}\right)$ with $\mathrm{OX}-0.6-10$ xerogel of different granulometry, before and after having been evacuated (results compiled in Figure 1). The aim of the degassing stage was to clear the porous structure of possible residual matter (mostly formaldehyde that did not completely react during the sol-gel process) and moisture, to prevent an adverse increase in the total thermal conductivity of the material. 


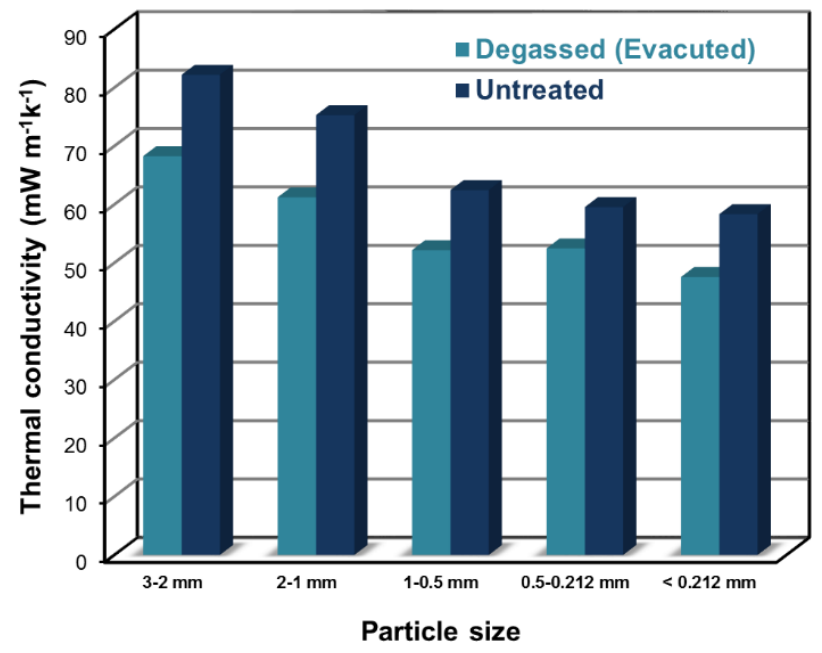

Fig 1 Thermal conductivity as a function of particle size for OX-0.6-10 xerogel, before (dark color) and after (light color) degassing

It is clear from Figure 1 that the thermal conductivity of the evacuated sample is lower. For all the particle sizes evaluated, the thermal conductivity has been reduced by around $17 \%$ due to the conditioning of the sample, i.e. treatment under high vacuum and moderate temperature $\left(0.1 \mathrm{mbar}\right.$ and $\left.120^{\circ} \mathrm{C}\right)$. This reduction is a result of the lower heat transfer by the convection mechanism, as it has been decreased the adsorbed molecules at the inner surface of the porous material. For this reason, the rest of the $\lambda$ values collected in the present work refer to degassed samples.

As regards granulometry, there is a clear decreasing tendency, with minimal thermal conductivity reaching $0.048 \mathrm{~W} \mathrm{~m}^{-1} \mathrm{k}^{-1}$ in the case of the evacuated organic xerogel with a particle size below $212 \mu \mathrm{m}$. The smaller the particle size, the greater the compaction of the material. Consequently, the gas volume interparticle is reduced. The contribution of gaseous thermal conduction is reduced and the insulating capacity of the material is improved. Thus, the maximum compaction degree of the material must be achieved in order to minimize the air contained between the particles. Therefore, other tests were performed using particle size ranges of $212-150,150-75,75-50$ and $<50 \mu \mathrm{m}$, but no improvement was observed with respect to the minimum value recorded for the particle sizes below $212 \mu \mathrm{m}$. Accordingly, for the other organic xerogels evaluated, no more divisions than those shown in Figure 1 were made.

\subsubsection{Effect of the bulk density}

Figure 2 shows the dependence of thermal conductivity on particle size for two samples 
of different density. The aim of this figure is to see whether granulometry produces the same effect on thermal conductivity in samples with diverse pore structures (volume/size of pores and, hence, different densities).

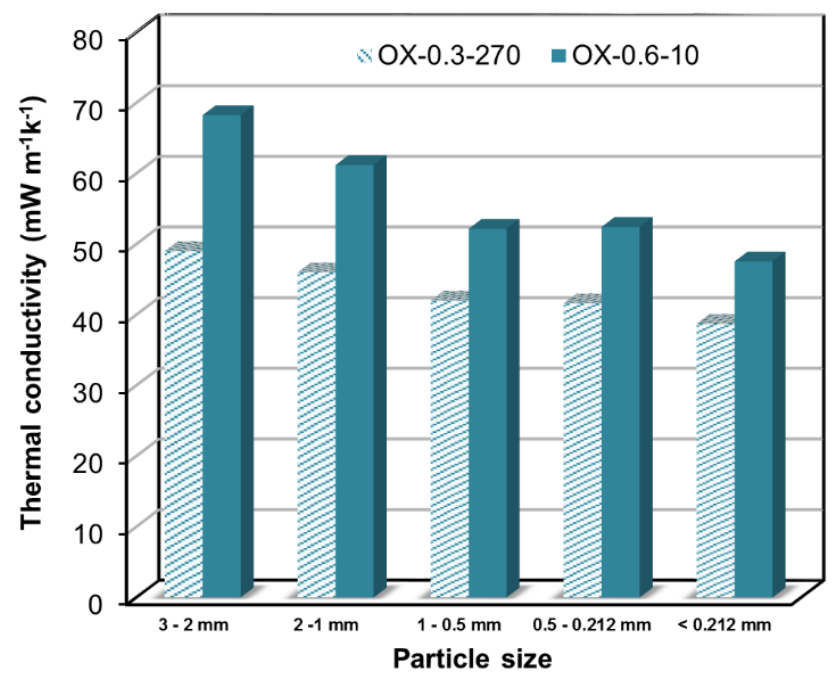

Fig 2 Dependence of thermal conductivity on particle size for two OX of different density

Regardless of the density, an improvement in the insulating capacity of the material (lower $\lambda$ value) occurs when the particle size decreases, although it should be noted that the improvement is more evident in the case of the sample with the higher density. As mentioned above, convection diminishes with particle size, whereas conduction does not change because the internal structure of the organic xerogels is not altered by the milling process. Because radiation is negligible and conduction is not modified, the total thermal conductivity is reduced due to the lower contribution of the convection mechanism. If the $\lambda$ values of both samples are compared, it can be seen that the organic xerogel of lower density (OX-0.3-270; $0.341 \mathrm{~g} \mathrm{~cm}^{-3}$ ) has associated lower thermal conductivity values than sample OX-0.6-10 (0.039 vs. $\left.0.048 \mathrm{~W} \mathrm{~m}^{-1} \mathrm{k}^{-1}\right)$. A low-density material has a smaller material load and, therefore, the number of interconnections between the clusters decreases, leading to lower thermal transmission by conduction.

To explore in greater depth the variation of thermal conductivity with density, the $\lambda$ values of five organic xerogels with different densities were determined. Figure 3 shows the $\lambda$ values obtained for samples previously degassed and screened to below $212 \mu \mathrm{m}$. These values of $\lambda$ vary from $0.039 \mathrm{~W} \mathrm{~m}^{-1} \mathrm{k}^{-1}$ for a low-density xerogel $\left(0.341 \mathrm{~g} \mathrm{~cm}^{-3}\right)$ to $0.064 \mathrm{~W} \mathrm{~m}^{-1} \mathrm{k}^{-1}$ in the case of the xerogel with the highest density, $0.732 \mathrm{~g} \mathrm{~cm}^{-3}$. As the density increases, the proportion of solid network also increases and, therefore, 
conduction through the solid phase is enhanced. Hence, in general terms, the variation of thermal conductivity can be considered as a function of bulk density.

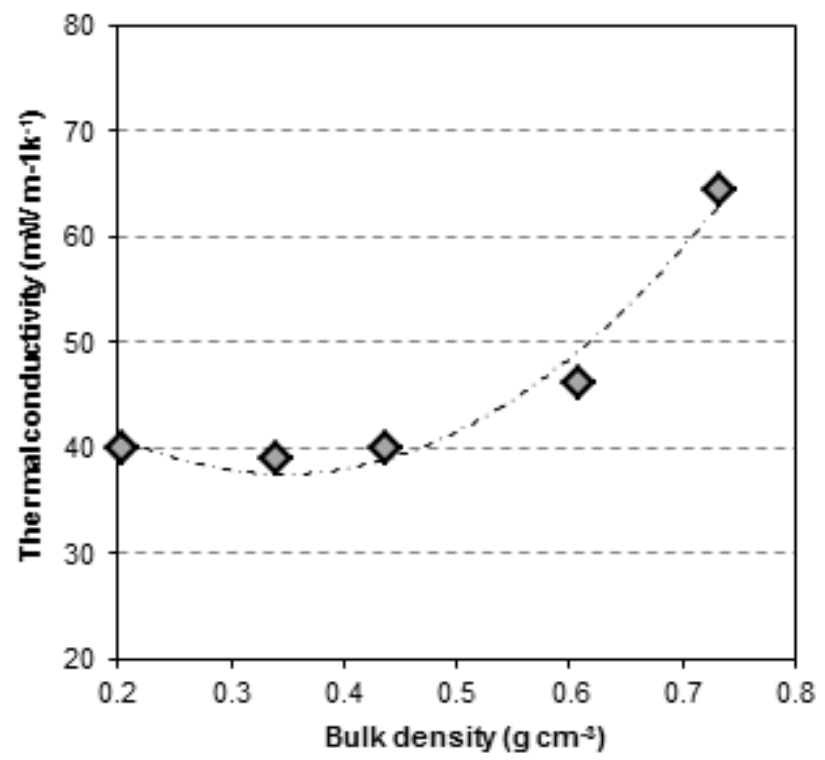

Fig 3 Conductivity values of five RF xerogels with different bulk density. Line is drawn as guides to the eyes

It seems clear that in order to obtain appreciable insulating properties, it is necessary to produce a material with low density. However, this is not the only determining factor. For example, virtually identical values of conductivity, 0.040 and $0.039 \mathrm{~W} \mathrm{~m}^{-1} \mathrm{k}^{-1}$, were registered for the organic xerogels OX-0.2-800 and OX-0.3-270, with densities of 0.204 and $0.341 \mathrm{~g} \mathrm{~cm}^{-3}$, respectively (Figure 3 ). The pore size distributions of both samples are recorded in Figure 4. The sample with the lower value of thermal conductivity (OX-0.3270) displays an average pore size centered at $270 \mathrm{~nm}$ compared to $800 \mathrm{~nm}$ for the less dense sample. It can be inferred from these data that the smaller the pore size, the less heat is transmitted by gaseous thermal conduction and, hence, the insulating properties of the material are improved. This example evidences the need for a trade-off between density and pore size in order to optimize the insulating character of the material; and indeed that was the ultimate goal of the present study, to evaluate the influence of pore size on the thermal conductivity of equally dense samples.

\subsubsection{Effect of the pore size}

In order to exclusively evaluate the effect of pore size, three organic xerogels of similar density $\left(\sim 0.2 \mathrm{~g} \mathrm{~cm}^{-3}\right)$ and different pore size distributions were selected (PSD collected 
in Figure 4). The $\lambda$ values of these samples, OX-0.2-5000, OX-0.2-800 and OX-0.2-144 are $0.044,0.040$ and $0.035 \mathrm{~W} \mathrm{~m}^{-1} \mathrm{k}^{-1}$, respectively. These results highlight the influence of pore size on the thermal conductivity of low-density samples. The value of $\lambda$ has been reduced by as much as $20 \%$, that is to say, the insulating capacity of the RF xerogel is enhanced when samples of equal density have a narrower pore size distribution. The improvement of the insulating properties with the reduction in pore size is due to the fact that smaller pores make heat transmission by gaseous thermal conduction more difficult.

The best insulating properties are exhibited by the RF xerogel with a bulk density of $0.248 \mathrm{~g} \mathrm{~cm}^{-3}$ and pore size of around $144 \mathrm{~nm}$, since it displays the smallest value of thermal conductivity, $0.035 \mathrm{~W} \mathrm{~m}^{-1} \mathrm{k}^{-1}$. It should be emphasized that this $\lambda$ value is close to that of expanded polystyrene (EPS, $0.034 \mathrm{~W} \mathrm{~m}^{-1} \mathrm{k}^{-1}$ ), the reference material selected for this study because it is one of the most commonly applied commercial insulating materials.

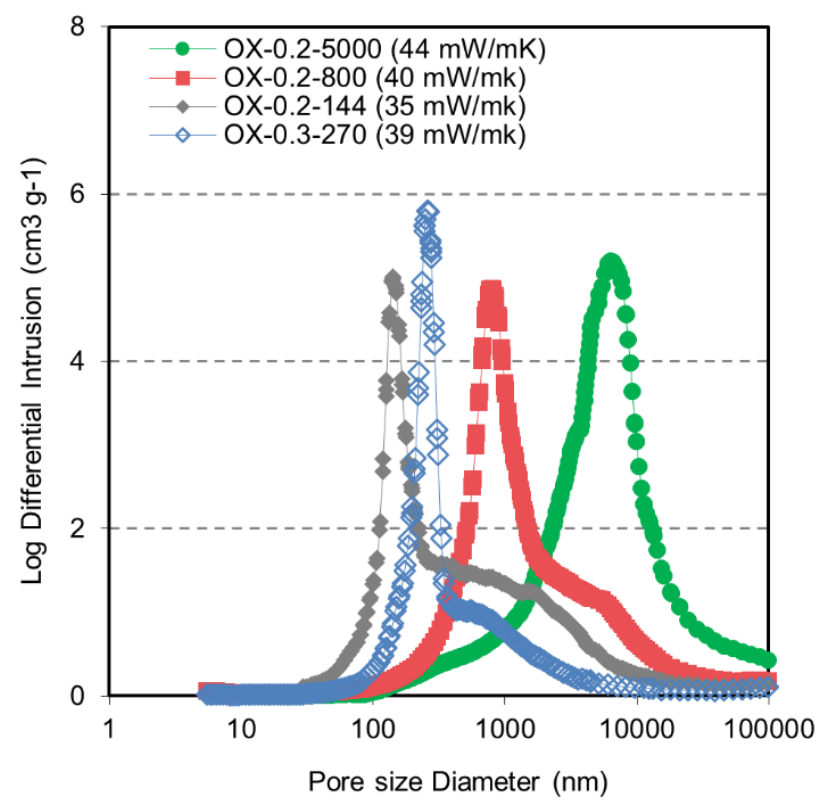

Fig 4 Pore size distribution of low-density xerogels (OX-0.2- $d_{p}$ and $\left.O X-0.3-270\right)$ recorded by mercury porosimetry

\section{Conclusions}

The main two mechanisms of heat transmission that contribute to the thermal conductivity of RF xerogels are solid thermal conduction and gaseous thermal conduction. The porous properties of these materials, particularly density and pore size, 
have the opposite influence on each of these mechanisms. It is necessary therefore to achieve a compromise between them so as to minimize the total thermal conductivity. On the one hand, density influences the mechanism of conduction because the lower the density, the fewer the interconnections between the material and, therefore, conduction through the solid is minimized. On the other hand, heat transmission by gaseous thermal conduction is reduced by decreasing pore size. Accordingly, by tailoring carefully the porosity of the materials, thermal conductivities close to that offered by expanded polystyrene, one of the most commonly employed commercial materials, were achieved (0.035 $\mathrm{W} \mathrm{m}^{-1} \mathrm{k}^{-1}$ for a RF xerogels vs. $0.034 \mathrm{~W} \mathrm{~m}^{-1} \mathrm{k}^{-1}$ for the EPS material). Thus, organic xerogels can be considered as a novel and attractive line of materials with good insulating properties since, in addition to reaching values similar to those of some commercial materials, thermal conductivity can be reduced by means of a meticulous design of the porous properties of RF xerogels, i.e. an appropriate combination of their density, pore volume and pore size.

\section{Acknowledgements}

The authors gratefully acknowledge the financial support of the Ministerio de Economía y Competitividad of Spain, MINECO (Projects IPT-2012-0689-420000, CTQ201349433-EXP, CTQ2014-54772-P). NRR also acknowledges a predoctoral research grant from MINECO.

\section{References}

[1] F. Asdrubali, F. D'Alessandro, S. Schiavoni, A review of unconventional sustainable building insulation materials, Sustainable. Mater.Technol., 4 (2015) 1-17.

[2] B.P. Jelle, Traditional, state-of-the-art and future thermal building insulation materials and solutions Properties, requirements and possibilities, Energy Build., 43 (2011) 2549-2563.

[3] S. Gutzov, N. Danchova, S.I. Karakashev, M. Khristov, J. Ivanova, J. Ulbikas, Preparation and thermal properties of chemically prepared nanoporous silica aerogels, J. Sol-Gel Sci. Technol., 70 (2014) 511-516.

[4] J.K. Lee, G.L. Gould, W. Rhine, Polyurea based aerogel for a high performance thermal insulation material, J. Sol-Gel Sci. Technol., 49 (2008) 209-220.

[5] E. Cuce, P.M. Cuce, C.J. Wood, S.B. Riffat, Toward aerogel based thermal superinsulation in buildings: A comprehensive review, Renewable Sustainable Energy Rev., 34 (2014) 273-299.

[6] R. Baetens, B.P. Jelle, J.V. Thue, M.J. Tenpierik, S. Grynning, S. Uvsløkk, A. Gustavsen, Vacuum insulation panels for building applications: A review and beyond, Energy Build., 42 (2010) 147-172.

[7] H. Zhang, W. Fang, Z. Li, W. Tao, The influence of gaseous heat conduction to the effective thermal conductivity of nano-porous materials, Int. Commun. Heat Mass Transfer, 68 (2015) 158-161.

[8] Y.-L. He, T. Xie, Advances of thermal conductivity models of nanoscale silica aerogel insulation material, Appl. Therm. Eng., 81 (2015) 28-50. 
[9] X. Lu, R. Caps, J. Fricke, C.T. Alviso, R.W. Pekala, Correlation between structure and thermal conductivity of organic aerogels, J. Non-Cryst. Solids, 188 (1995) 226-234.

[10] F. Hemberger, S. Weis, G. Reichenauer, H.-P. Ebert, Thermal Transport Properties of Functionally Graded Carbon Aerogels, Int. J. Thermophys., 30 (2009) 1357-1371.

[11] M. Wiener, G. Reichenauer, S. Braxmeier, F. Hemberger, H.P. Ebert, Carbon Aerogel-Based HighTemperature Thermal Insulation, Int. J. Thermophys., 30 (2009) 1372-1385.

[12] A. Allahbakhsh, A.R. Bahramian, Self-assembled and pyrolyzed carbon aerogels: an overview of their preparation mechanisms, properties and applications, Nanoscale, 7 (2015) 14139-14158.

[13] K. Guo, Z. Hu, H. Song, X. Du, L. Zhong, X. Chen, Low-density graphene/carbon composite aerogels prepared at ambient pressure with high mechanical strength and low thermal conductivity, RSC Adv., 5 (2015) 5197-5204.

[14] M. Wiener, G. Reichenauer, F. Hemberger, H.P. Ebert, Thermal Conductivity of Carbon Aerogels as a Function of Pyrolysis Temperature, Int. J. Thermophys., 27 (2006) 1826-1843.

[15] X. Lu, M.C. Arduini-Schuster, J. Kuhn, O. Nilsson, J. Fricke, R.W. Pekala, Thermal conductivity of monolithic organic aerogels, Science, 255 (1992) 971-972.

[16] J. Feng, J. Feng, C. Zhang, Thermal conductivity of low density carbon aerogels, J. Porous Mater., 19 (2011) 551-556.

[17] R. Tannert, M. Schwan, L. Ratke, Reduction of shrinkage and brittleness for resorcinolformaldehyde aerogels by means of a pH-controlled sol-gel process, J. Supercrit. Fluids, 106 (2015) 5761.

[18] C. Bi, G.H. Tang, W.Q. Tao, Prediction of the gaseous thermal conductivity in aerogels with nonuniform pore-size distribution, J. Non-Cryst. Solids, 358 (2012) 3124-3128.

[19] J. Feng, J. Feng, Y. Jiang, C. Zhang, Ultralow density carbon aerogels with low thermal conductivity up to $2000^{\circ} \mathrm{C}$, Mater. Lett., 65 (2011) 3454-3456.

[20] N. Rey-Raap, J.A. Menéndez, A. Arenillas, Simultaneous adjustment of the main chemical variables to fine-tune the porosity of carbon xerogels, Carbon, 78 (2014) 490-499.

[21] E.G. Calvo, E.J. Juarez-Perez, J.A. Menendez, A. Arenillas, Fast microwave-assisted synthesis of tailored mesoporous carbon xerogels, J. Colloid Interface Sci., 357 (2011) 541-547.

[22] V. Bock, O. Nilsson, J. Blumm, J. Fricke, Thermal properties of carbon aerogels, J. Non-Cryst. Solids, 185 (1995) 233-239.

[23] O. Czakkel, K. Marthi, E. Geissler, K. László, Influence of drying on the morphology of resorcinolformaldehyde-based carbon gels, Micropor. Mesopor. Mater., 86 (2005) 124-133.

[24] N. Rey-Raap, A. Arenillas, J.A. Menéndez, A visual validation of the combined effect of $\mathrm{pH}$ and dilution on the porosity of carbon xerogels, Micropor. Mesopor. Mater., 223 (2016) 89-93.

[25] N. Rey-Raap, J.A. Menéndez, A. Arenillas, RF xerogels with tailored porosity over the entire nanoscale, Micropor. Mesopor. Mater., 195 (2014) 266-275.

[26] N. Rey-Raap, S. Rodríguez-Sánchez, I.D. Alonso-Buenaposada, E.G. Calvo, J.A. Menéndez, A. Arenillas, The enhancement of porosity of carbon xerogels by using additives, Micropor. Mesopor. Mater., 217 (2015) 39-45.

[27] N. Rey-Raap, J.A. Menéndez, A. Arenillas, Optimization of the process variables in the microwaveinduced synthesis of carbon xerogels, J. Sol-Gel Sci. Technol., (2013) 1-10. 